\title{
Physical Activity, Obesity, and COVID-19: What can we Expect from his Relationship?
}

\author{
Ciro Oliveira Queiroz, ${ }^{\circledR}$ Ariani França Conceição, ${ }^{1 \oplus}$ Paulo Rodrigo Santos Aristides, ${ }^{1}$ Leandro Silva Alves, ${ }^{2}{ }^{\circledR}$
} Rogério Tosta Almeida ${ }^{3,4}$

Escola Bahiana de Medicina e Saúde Pública, 'Salvador, BA - Brazil

Universidade de São Paulo, ${ }^{2}$ São Paulo, SP - Brazil

Universidade Estadual de Feira de Santana, Feira de Santana, ${ }^{3} B A-$ Brazil

Universidade Federal da Bahia - Instituto de Saúde Coletiva, ${ }^{4}$ Salvador, BA-Brazil

The COVID-19 pandemic is a public health problem, whose first cases were found in Wuhan, China, in December, 2019, and which is currently present around the world. ${ }^{1}$ COVID-19 is caused by the new coronavirus (SARSCoV-2), which shows a high potential of contamination. Its transmission occurs through droplets during unprotected proximity with an infected person and contact with contaminated environmental surfaces, which are the main systemic and respiratory symptoms. ${ }^{1,2}$

To date, there is no pharmacological treatment that has proven to be effective, or a vaccine for the prevention or treatment of COVID-19. Thus, a non-pharmacological strategy of public health, which has shown effectiveness in the exponential control of the disease, is social distancing, which encompasses the isolation of cases, quarantine of contacts, and the voluntary practice of not going to crowed places. ${ }^{3}$ These measures have demonstrated that they can reduce mortality rates during the pandemic, and they have helped in governmental decision-making.,

Although the lethality rate of COVID-19 varies among countries, mortality most commonly occurs among the elderly or people with comorbidities, such as cardiovascular diseases, diabetes, cancer, and chronic pulmonary diseases. ${ }^{5,6}$ In a recent study in the city of Wuhan, China, obesity was not reported as a pre-existing comorbidity, which favored the increase in the general lethality rate in patients with COVID-19. ${ }^{5}$

However, a study conducted in New York pointed out that approximately $41.7 \%$ of all hospitalized

\section{Keywords}

COVID-19; Coronavirus; Exercise; Obesity. patients were obese, it being among the three most common comorbidities of the infected people. ${ }^{7}$ This divergency of data among the countries can be justified by the demographic characteristics and prevalence of comorbidities of each population. ${ }^{8}$ The Center for Disease Control and Prevention (CDC) considers that people with severe obesity (Body Mass Index (BMI) $\geq 40$ $\left.\mathrm{Kg} / \mathrm{m}^{2}\right)$, can present greater risks for the worsening of COVID-19. ${ }^{9}$

Some common connections between SARS-CoV-2 and obesity are respiratory problems. It is well-known that there is a positive correlation among asthma, acute lung injury, obstructive sleep apnea syndrome, acute respiratory distress syndrome, and being overweight. ${ }^{10}$ Obesity is associated with a decrease in functional capacity, as well as with a compliance of the respiratory system and the expiratory reserve volume. ${ }^{11}$

In France, data from patients that made use of invasive mechanical ventilation have shown that individuals with severe obesity $\left(\mathrm{BMI} \geq 35 \mathrm{Kg} / \mathrm{m}^{2}\right)$ presented impaired respiratory patterns in relation to the patients with $\mathrm{BMI} \leq 25 \mathrm{Kg} / \mathrm{m}^{2}{ }^{12}$ In this scenerio, obesity represents an independent risk factor for the respiratory hypoventilation syndrome, a potential aggravating factor for complications related to respiratory insufficiency in patients who are admitted to intensive care units. ${ }^{13}$

Beyond respiratory complications, another liaison with COVID-19 is inflammation. Obesity causes an increase of secretion of pro-inflammatory cytokines in the adipose tissue, which can worsen if infected by COVID-19. ${ }^{10,11,14}$ High serum levels of interleukin-6 (IL-6) have been reported in patients who passed away

Mailing Address: Ciro Oliveira Queiroz

Escola Bahiana de Medicina e Saúde Publica

Rua Silveira Martins, n 3386. Postal Code: 41150-100, Cabula, Salvador, BA - Brazil.

E-mail: ciroedfisica@gmail.com 
due to COVID-19. ${ }^{6}$ In addition to IL-6, the receptors of interleukin-2 and the tumor necrosis factor-alpha can also take part in endothelial dysfunction. ${ }^{15}$

Another important point to be highlighted is the relationship between obesity with cardiovascular diseases/events, such as hypertension, stokes, heart failure, and coronary artery disease, as well as diabetes. However, what has most called attention in this scenario is thrombosis, since obesity can increase the risk of developing this type of blood clot, and, together with COVID-19, it can further aggravate the situation through intravascular coagulation and an increase in the rates of venous thromboembolism. ${ }^{10}$ Moreover, a high incidence of cardiovascular symptoms can be observed due to the systemic inflammatory response and the changes caused by the immune system during the course of COVID-19. ${ }^{16}$

Thus, the reduction of body weight, despite not reducing the risk of infection, seems to be an important preventive and protective measure against serious cases of SARS-CoV-2, as it favors a decrease in inflammatory processes caused by obesity. Despite the need for more consistent evidence of the protective effect of the regular practice of physical activity and healthy diets in a population contaminated by SARS$\mathrm{CoV}-2,{ }^{17}$ these types of behaviors are acknowledged in the literature as effective for the control of obesity in the general population. ${ }^{18}$ It has also been speculated that individuals with desirable levels of cardiorespiratory aptitude tend to show a higher protection against the symptoms caused by the SARS-CoV-2 infection, mainly due to an enhanced immunological resistance. ${ }^{19}$

Another issue that requires close attention is the possibility of an increase in sedentary behaviors, such as sitting in front of a TV or spending time with electronic gadgets, as these seem to be associated with various chronic non-communicable diseases and cardiovascular mortality. ${ }^{20}$

Thus, with the needed recommendations of social distancing, it is feared that the population may reduce the practice of physical activity and increase sedentary behaviors and body weight, even further worsening the scenario of a global endemic of obesity, which could, in the mid-term, at least while there is not a more efficient treatment or the discovery of a definitive vaccine, increase the risk of more complications because of the disease and cause an overload in the health system. Moreover, it is still true that the recommendation of global scientific and health entities is to avoid agglomerations in situations with a high possibility of the transmission of the virus, such as gyms and sports centers, in municipalities and regions that need interventions to flatten the contagion curve.

In this sense, the stimulus for the practice of regular outdoor, or in-home, physical activities for all ages must be better widespread and conveyed, respecting the advice from health authorities and governmental decrees regarding the continuance of social distancing. This is an important message of public health in order to maintain physical and mental health and to cope with this moment of generalized anxiety and the feeling of hopelessness.

There are many alternatives for the practice of physical activities - ones that do not require the use of equipment and that can be done in a family and household environment; however, people need to be encouraged and properly advised. Such activities include aerobic activities, such as dancing, stationary racing, and walking up and down stairs, as well as activities of muscular strength/resistance, which make use of different areas of the body, including yoga, Pilates, and training with body weight (squatting, burpees, sit-ups, ground support, etc.).

Many physical education professionals are already using messages in mobile phones, apps, e-mails, or video calls to prescribe and monitor exercises individually. ${ }^{21}$ There are also free initiatives for the guidance of physical activities on the internet, many of which are connected to universities or nongovernmental organizations, according to guidelines set forth by the World Health Organization (WHO), ${ }^{22}$ for example, which could be implemented by governments, with mass educational campaigns, freely broadening this message to the entire population.

It is is also important to highlight the need for the maintenance of the practice of physical activity for the elderly, as they tend to have a higher number of chronic, primarily cardiovascular, diseases, and they are more vulnerable to complications caused by SARSCoV-2. Nevertheless, if symptoms related to COVID-19 appear, the practice of physical activity should be interrupted, regardless of the age group. ${ }^{21,23}$ The PreExercise Screening Questionnaire (PESQ), considering the presence of signs and symptoms, was proposed to the current context as an additional tool for initial screening for a safer practice of telepresence exercise. ${ }^{21}$ 
Therefore, it seems that the regular practice of physical activities can aid in the control of obesity, beyond favoring an enhanced immunological response for the current moment of the COVID-19 pandemic. Public health policies should provide assistance not only for individuals, but also for the public in general. They should help people either to continue or become physically active, encouraging people's autonomy and independence, taking into consideration the differences between groups and iniquities in health. These policies are emerging, are of utmost importance and, will become an ever-increasingly important part of the "new normal".

Finally, this moment of the COVID-19 pandemic may be an opportunity for reflection on our behaviors and individual and collective care related to health. In general, periods of social distancing are not experienced over the long term; however, the decision-making concerning our choices can and should be undertaken throughout our entire life.

\section{Author contributions}

Conception and design of the research: Queiroz CO, Conceição AF, Aristides PRS, Alves, LS, Almeida

\section{References}

1. World Health Organization. Report of the WHO-China Joint Mission on Coronavirus Disease 2019 (COVID-19). Geneva: World Health Organization; 2020.

2. Pascarella G, Strumia A, Piliego C, Bruno F, Del Buono R, Costa F, et al. COVID-19 Diagnosis and Management: A Comprehensive Review. J Intern Med. 2020;288(2):192-206. doi: 10.1111/joim.13091.

3. Natividade MDS, Bernardes K, Pereira M, Miranda SS, Bertoldo J, Teixeira MDG, et al. Social Distancing and Living Conditions in the Pandemic COVID-19 in Salvador-Bahia, Brazil. Cien Saude Colet. 2020;25(9):338592. doi: 10.1590/1413-81232020259.22142020.

4. Nussbaumer-Streit B, Mayr V, Dobrescu AI, Chapman A, Persad E, Klerings I, et al. Quarantine Alone or in Combination with Other Public Health Measures to Control COVID-19: A Rapid Review. Cochrane Database Syst Rev. 2020;9(9):1-75. doi: 10.1002/14651858.CD013574.pub2.

5. Wu Z, McGoogan JM. Characteristics of and Important Lessons From the Coronavirus Disease 2019 (COVID-19) Outbreak in China: Summary of a Report of 72314 Cases From the Chinese Center for Disease Control and Prevention. JAMA. 2020;323(13):1239-42. doi: 10.1001/jama.2020.2648.

6. Zhou F, Yu T, Du R, Fan G, Liu Y, Liu Z, et al. Clinical Course and Risk Factors for Mortality of Adult Inpatients with COVID-19 in Wuhan, China: A Retrospective Cohort study. Lancet. 2020;395(10229):1054-62. doi: 10.1016/S0140-6736(20)30566-3.

7. Richardson S, Hirsch JS, Narasimhan M, Crawford JM, McGinn T, Davidson KW, et al. Presenting Characteristics, Comorbidities, and Outcomes Among 5700 Patients Hospitalized with COVID-19 in the New York City Area. JAMA. 2020;323(20):2052-9. doi: 10.1001/jama.2020.6775.

8. Institute for Health Metrics and Evaluation. GBD Compare/Viz Hub [Internet]. 2020 [cited 2021 Jul 26]. Available from: https://vizhub. healthdata.org/gbd-compare/
RT. Acquisition of data: Queiroz CO, Conceição AF, Almeida RT. Writing of the manuscript: Queiroz $\mathrm{CO}$, Conceição AF, Almeida RT Critical revision of the manuscript for intellectual content: Queiroz CO, Conceição AF, Aristides PRS, Alves, LS, Almeida RT.

\section{Potential Conflict of Interest}

No potential conflict of interest relevant to this article was reported.

\section{Sources of Funding}

There were no external funding sources for this study.

\section{Study Association}

This study is not associated with any thesis or dissertation work.

\section{Ethics approval and consent to participate}

This article does not contain any studies with human participants or animals performed by any of the authors.

9. Coronavirus Disease 2019 (COVID-19)/People Who Are at Higher Risk for Severe Illness. [Internet]. Atlanta: Center for Disease Control and Prevention; 2020 [cited 2021 Jul 26]. Available from: https://www.cdc. gov/coronavirus/2019-ncov/need-extra-precautions/people-at-higherrisk.html.

10. Watanabe M, Risi R, Tuccinardi D, Baquero CJ, Manfrini S, Gnessi L. Obesity and SARS-CoV-2: A Population to Safeguard. Diabetes Metab Res Rev. 2020:e3325. doi: 10.1002/dmrr.3325.

11. Dietz W, Santos-Burgoa C. Obesity and its Implications for COVID-19 Mortality. Obesity. 2020;28(6):1005. doi: 10.1002/oby.22818.

12. Simonnet A, Chetboun M, Poissy J, Raverdy V, Noulette J, Duhame A, et al. High Prevalence of Obesity in Severe Acute Respiratory Syndrome Coronavirus-2 (SARS-CoV-2) Requiring Invasive Mechanical Ventilation. Obesity. 2020;28(7):1195-9. doi: 10.1002/ oby. 22831.

13. Marik PE, Chen C. The Clinical Characteristics and Hospital and Post-Hospital Survival of Patients With the Obesity Hypoventilation Syndrome: Analysis of a Large Cohort. Obes Sci Pract. 2016;2(1):40-7. doi: 10.1002/osp4.27.

14. Grant WB, Lahore H, McDonnell SL, Baggerly CA, French CB, Aliano JL, et al. Evidence that Vitamin D Supplementation Could Reduce Risk of Influenza and COVID-19 Infections and Deaths. Nutrients. 2020;12(4):988. doi: 10.3390/nu12040988.

15. Pons S, Fodil S, Azoulay E, Zafrani L. The Vascular Endothelium: The Cornerstone of Organ Dysfunction in Severe SARS-CoV-2 Infection. Crit Care. 2020;24(1):353. doi: 10.1186/s13054-020-03062-7.

16. Ferrari F. COVID-19: Updated Data and its Relation to the Cardiovascular System. Arq Bras Cardiol. 2020;114(5):823-6. doi: 10.36660/abc. 20200215. 
17. Kenyon C. The Forrest Gump Approach to Preventing Severe COVID-19 Reverse the Predisposing Pro-Inflammatory State with Exercise. Microbes Infect. 2020;22(4-5):151-3. doi: 10.1016/j.micinf.2020.05.003.

18. Petridou A, Siopi A, Mougios V. Exercise in the Management of Obesity. Metabolism. 2019;92:163-9. doi: 10.1016/j.metabol.2018.10.009.

19. Zbinden-Foncea H, Francaux M, Deldicque L, Hawley JA. Does High Cardiorespiratory Fitness Confer Some Protection Against Proinflammatory Responses After Infection by SARS-CoV-2? Obesity. 2020;28(8):1378-81. doi: 10.1002/oby.22849.

20. Patterson R, McNamara E, Tainio M, Sá TH, Smith AD, Sharp SJ, et al. Sedentary Behaviour and Risk of All-Cause, Cardiovascular and Cancer Mortality, and Incident Type 2 Diabetes: A Systematic Review and Dose Response Meta-Analysis. Eur J Epidemiol. 2018;33(9):811-29. doi: 10.1007/ s10654-018-0380-1.
21. Oliveira Neto L, Tavares VDO, Schuch FB, Lima KC. Coronavirus Pandemic (SARS-COV-2): Pre-Exercise Screening Questionnaire (PESQ) for Telepresential Exercise. Front Public Health. 2020;8:146. doi: 10.3389/ fpubh.2020.00146.

22. Stay Physically Active During Self-Quarantine. [Internet]. Geneva: World Health Organization; 2020. [cited 23 Jul 2021]. Available from: http:// www.euro.who.int/en/health-topics/health-emergencies/coronaviruscovid-19/novel-coronavirus-2019-ncov-technical-guidance-OLD/stayphysically-active-during-self-quarantine.

23. Ferreira MJ, Irigoyen MC, Consolim-Colombo F, Saraiva JFK, Angelis K. Physically Active Lifestyle as an Approach to Confronting COVID-19. Arq Bras Cardiol. 2020;114(4):601-2. doi: 10.36660/abc.20200235. 